\title{
HBsAg Positive Patient Characteristics in Hospital and Blood Donation Camps
}

\author{
Deepti Sachan, ${ }^{1}$ Joy Varghese, ${ }^{2}$ Jensingh Joseph, ${ }^{3}$ \\ Vijaya Srinivasan, ${ }^{2}$ Venkataraman Jayanthi, ${ }^{2}$ and Mohamed Rela ${ }^{2}$ \\ ${ }^{1}$ Department of Transfusion Medicine, Global Hospitals \& Health City, Chennai, India \\ ${ }^{2}$ Department of Hepatology \& Liver Transplantation, Global Hospitals \& Health City, Chennai 600 100, India \\ ${ }^{3}$ Department of Gastroenterology \& Hepatology, Kamakshi Memorial Hospital, Chennai 600 100, India
}

Correspondence should be addressed to Joy Varghese; joyvargese@gmail.com

Received 28 May 2013; Accepted 1 August 2013

Academic Editors: D. L. Baker, A. Bosly, and A. Gatt

Copyright (c) 2013 Deepti Sachan et al. This is an open access article distributed under the Creative Commons Attribution License, which permits unrestricted use, distribution, and reproduction in any medium, provided the original work is properly cited.

\begin{abstract}
Background. Prevention of the residual risk of transfusion transmitted hepatitis B virus infection (HBV) is mostly dependant on serological screening of blood donors for HBsAg and antibody to hepatitis B core antigen (anti-HBc Ab). This study aimed to study the prevalence of $\mathrm{HBsAg}$ and anti-HBc Ab and to compare the profile of blood donors attending a blood donation camp and people attending a hospital based camp. Methods. In the blood donor camp, all the blood units were screened for HBV, (HBsAg and anti-HBc), and in the hospital based camp, screening was done for HBsAg alone. Baseline demographic characteristics were noted. Results. The number of blood bank donors was 363 (47.5\%) and hospital camp attendees was 402 (52.5\%). Prevalence of HBsAg positivity was similar in both the groups at $1.7 \%$ and $1.9 \%$, respectively. Anti-HBc Ab positivity (Total) was $6 \%$ among the blood donors; Overall prevalence of HBV infection in this group was 3.2\%. Conclusion. Policy for checking the collected blood unit by 3 tests for anti-HBc, anti-HBsAb, and HBsAg should be reconsidered to possibly achieve the zero risk goal of transfusion transmitted $\mathrm{HBV}$ infection. Blood obtained from a vaccinated donor may give an added protection to the recipient.
\end{abstract}

\section{Introduction}

Hepatitis B virus (HBV) is one of the most common cause for chronic liver disease (CLD) in the developing countries. The virus is known to be highly infective and is associated with long-term morbidity and mortality due to complications like cirrhosis, portal hypertension, and hepatocellular carcinoma (HCC). Prevalence of hepatitis B surface antigen (HBsAg) in India varies from 1 to 13 percent, with an average of 4.7 percent [1-6].

Community-based prevalent studies in a selective population in Tamil Nadu state have shown prevalence of HBV infection in adults to be $27.4 \%$ and $32.7 \%$ in the younger age group (15 to 20 years) [7]. In another single community-based study from North India, consisting of 730 subjects (rural = 543; urban $=187)$, HBsAg was positive in $15(2.1 \%)$ and anti$\mathrm{HBc}$ in 143 (19.5\%); 10 were positive for both. The overall HBV exposure rate in the population was 20.3\% (148/730). The HBsAg carrier rate was similar in the urban and rural populations (1.5\% and $2.3 \%$, and not significant), and anti$\mathrm{HBc}$ positivity was lower in the urban population $(8.5 \%$ versus $23.3 \% ; P<0.01)[8]$.

Transmission of HBV infection through donated blood ranges from $1.2 \%$ to $1.7 \%$. In the developing world, it is one of the major concerns in the field of transfusion medicine [9-11]. Most blood banks seldom screen for anti-HBc in the blood donors. Anti-HBc positivity indicates past HBV infection. Replacement of this blood in an immunocompromised individual can result in reactivation of the virus.

\section{Methods}

The World Hepatitis Day was held on 24 August 2013. As part of the program, a screening camp for HBsAg was held in the hospital campus of Dr Kamakshi Memorial Hospital, Chennai, and a blood donation camp was held at Global Health City, Chennai. 
In the blood donor camp, all the blood units were screened for $\mathrm{HBV}$ (HBsAg and anti-HBc), hepatitis $\mathrm{C}$ virus (HCV), human immunodeficiency virus (HIV) 1 and 2, HIV p24, venereal disease research laboratory (VDRL), and malaria. The data of HBsAg and anti-Hbc alone was analyzed for this study. In the hospital based camp, screening was done for $\mathrm{HBsAg}$ alone.

Apart from ascertaining the prevalence of $\mathrm{HBV}$ infection in these two groups, we obtained further additional information on demographic profile such as age, gender, occupation, type of house, amenities in the house, previous history of jaundice or known CLD, surgery, tattoo, family history of liver disease including HCC, previous blood donations, and details of $\mathrm{HBV}$ vaccination.

The data was collected in a standardized pretested proforma, by trained health workers (nurses and auxiliary health personnel).

2.1. Statistical Tests. Comparison of the two groups was done using parametric tests such as chi-square, test of proportion, Student's $t$-test, analysis of variance, and parametric tests such as Wilcoxan Sign Rank Sum test.

\section{Results}

The number of blood bank donors (BBD) was 363 (47.5\%) and hospital camp attendees was 402 (52.5\%). Most of the $\mathrm{BBD}$ participants were adults in the age range $18-58$ years (median 25.5 years), and the majority were men (90.9\%). In the hospital based camp (HBC) there were children $(2.2 \%)$ and adults. Their age ranged from 7 to 76 years (median 23.5 years); two thirds were men $(2: 1)$. The age difference in the two population groups was significant with the donors being predominantly young adults (sign rank sum test $P<0.01$ ). Among the BBD, one-third-were information Technology (IT) professionals holding white collar jobs (31.7\%), and another one-third (37.2\%), were skilled workers; college students formed $16.3 \%$. HBC attendees were primarily hospital staff (60.5\%), two-thirds of whom were auxiliary staff; doctors and nurses constituted $25.9 \%$. The occupation of the two groups (BBD versus $\mathrm{HBC}$ ) was significantly different (Chi square $P<0.001)$. Fifty percent of the BBD (51\%) had donated blood in the past as against 7\% amongst $\mathrm{HBC}$ attendees $\left(P<10^{-5}\right)$. There was no history of drug abuse in either group.

Previous history of surgery was significantly low amongst the BBD compared to HBC attendees $(1.6 \%$ versus $5.8 \%)(P<$ $0.01)$.

Prevalence of HBsAg positivity was similar in both the groups at $1.7 \%$ and $1.9 \%$, respectively. Core antigen prevalence as measured by total anti-HBc positivity was $6 \%$ among the $\mathrm{BBD}$. Overall prevalence of $\mathrm{HBV}$ infection in this group was $3.2 \%$.

Fewer individuals were vaccinated against $\mathrm{HBV}$ infection in the $\mathrm{BBD}$ group (10.5\%) compared to $27.3 \%$ among $\mathrm{HBC}$ attendees $(P<0.001)$.

There was only one blood donor who had received HBV prophylaxis in the past and had an accidental needle prick prior to blood donation.
In the $\mathrm{HBC}$ group, vaccination rates among the hospital employees and the nonhospital attendees were similar at $28.0 \%$ and $26.3 \%$ (NS), respectively. Also, $50 \%$ of those who had donated blood in this group (HBC) in the past were protected with hepatitis $\mathrm{B}$ vaccine compared to those who had not donated blood (only $25.5 \%$ protected; $P<0.005$ ).

Factors such as family history of liver disease, past history of jaundice, and the number of blood transfusion received were similar in both groups.

\section{Discussion}

The present study has highlighted differences in individual characteristics between two camps: $\mathrm{BBD}$ and $\mathrm{HBC}$, in the presence of similar HBsAg prevalence in the two groups. Anti-HBc detection in the BBD group further increased the $\mathrm{HBV}$ prevalence to $3.2 \%$. Varying prevalence of antiHBc, a marker for exposure to $\mathrm{HBV}$ infection, has been reported from different parts of India, ranging between $8 \%$ and $18 \%$ of total donor population. In a study [12] from Behrampur, Ganjam in Orissa, 220 of 729 study population were antiHBc positive $(30.1 \%)$ indicating a very high rate of exposure to $\mathrm{HBV}$ infection among the blood donors from this region. A significant number of them were anti-HBs positive.

Addition of HBV DNA and nucleic acid testing (NAT) is likely to further increase the prevalence of chronic HBV infection in the community. Screening all our blood donors with all these tests is practically challenging issue. Failure to utilize this donor pool would result in further shortage of blood pool. The above tests may be appropriate in especial settings, for example, blood transfusion in an immunosuppressant or a posttransplant individual.

The blood donors in our study were young adults, mostly males, primarily students or IT professionals or working class, with almost 50\% having donated blood in the past.

Only $10 \%$ of individuals in the blood donation camp were vaccinated against HBV. One would have expected a much larger proportion of individuals in hospital camp attendees to be vaccinated. This was not so. Only one-third of these were vaccinated. The poor vaccination status amongst young adults should be an eye opener for health authorities to undertake the task of mass vaccination campaign across the country, if one was to curtail HBV infection. There is a need for nationwide "Awareness Program" and stringent vaccination programs for both the high risk hospital professionals and also those belonging to the general population.

\section{Conclusion}

Policy for checking the collected blood unit by 3 tests for anti-HBc, anti-HBsAb, and $\mathrm{HBsAg}$ should be reconsidered to possibly achieve the zero risk goal of transfusion transmitted $\mathrm{HBV}$ infection. Blood obtained from a vaccinated donor may give an added protection to the recipient.

\section{Abbreviations}

BBD: Blood bank donors

HBsAg: Hepatitis B surface antigen 
HBC: $\quad$ Hospital based camp

HBV: $\quad$ Hepatitis B virus

anti-HBc Ab: Antibody to HBcore antigen

anti-HBsAb: Anti HBs antibody

HCC: Hepatocellular carcinoma

HCV: $\quad$ Hepatitis $\mathrm{C}$ virus

HIV: Human immunodeficiency virus

HTLV: Human T-cell lymphotropic virus

VDRL: Venereal disease research laboratory.

\section{References}

[1] S. P. Thyagarajan, S. Jayaram, and B. Mohanavalli, "Prevalence of HBV in general population of India," in Hepatitis B in India: Problems and Prevention, S. K. Sarin and A. K. Singhal, Eds., pp. 5-16, CBS, New Delhi, India, 1996.

[2] R. C. Jain, S. D. Bhat, and S. Sangle, "Prevalence of hepatitis surface antigen among rural population of Loni area in Ahmednagar district of Western Maharashtra," The Journal of the Association of Physicians of India, vol. 40, no. 6, pp. 390-391, 1992.

[3] S. R. Pal, N. L. Chitkara, S. Choudhury, D. V. Dutta, S. D. Deodhar, and P. N. Chhuttani, "Hepatitis B virus infection in Northern India. Prevalence, subtypes, and seasonal variation," Bulletin of the World Health Organization, vol. 51, no. 1, pp. 13-17, 1974.

[4] V. N. Mital, O. P. Gupta, D. K. Nigam, P. C. Saxena, and S. Kumar, "Pattern of hepatitis B antigen-contact and carrier state in Northern India," Journal of the Indian Medical Association, vol. 74, no. 6, pp. 105-107, 1980.

[5] O. Sobeslavsky, "Prevalence of markers of hepatitis B virus infection in various countries: a WHO collaborative study," Bulletin of the World Health Organization, vol. 58, no. 4, pp. 621628, 1980.

[6] B. N. Tandon, M. Irshad, M. Raju, G. P. Mathur, and M. N. Rao, "Prevalence of HBsAg and anti-HBs in children and strategy suggested for immunisation in India," Indian Journal of Medical Research A, vol. 93, pp. 337-339, 1991.

[7] T. Kurien, S. P. Thyagarajan, L. Jeyaseelan et al., "Community prevalence of hepatitis B infection \& modes of transmission in Tamil Nadu, India," Indian Journal of Medical Research, vol. 121, no. 5, pp. 670-675, 2005.

[8] H. Singh, R. Aggarwal, R. L. Singh, S. R. Naik, and S. Naik, "Frequency of infection by hepatitis B virus and its surface mutants in a Northern Indian population," Indian Journal of Gastroenterology, vol. 22, no. 4, pp. 132-137, 2003.

[9] M. Meena, T. Jindal, and A. Hazarika, "Prevalence of hepatitis $\mathrm{B}$ virus and hepatitis $\mathrm{C}$ virus among blood donors at a tertiary care hospital in India: a five-year study," Transfusion, vol. 51, no. 1, pp. 198-202, 2011.

[10] P. A. Giri, J. D. Deshpande, D. B. Phalke, and L. B. Karle, "Seroprevalence of transfusion transmissible infections among voluntary blood donors at a tertiary care teaching hospital in rural area of India," Journal of Family Medicine and Primary Care, vol. 1, no. 1, pp. 48-51, 2012.

[11] K. Singh, S. Bhat, and S. Shastry, "Trend in seroprevalence of hepatitis B virus infection among blood donors of coastal Karnataka, India," Journal of Infection in Developing Countries, vol. 3, no. 5, pp. 376-379, 2009.

[12] R. Panigrahi, A. Biswas, S. Datta et al., "Anti-hepatitis B core antigen testing with detection and characterization of occult hepatitis B virus by an in-house nucleic acid testing among blood donors in Behrampur, Ganjam, Orissa in southeastern India: implications for transfusion," Virology Journal, vol. 7, article 204, 2010. 


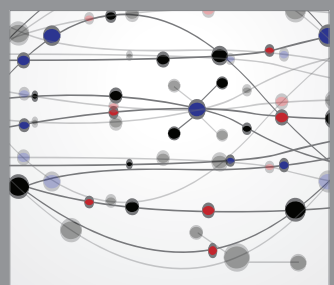

The Scientific World Journal
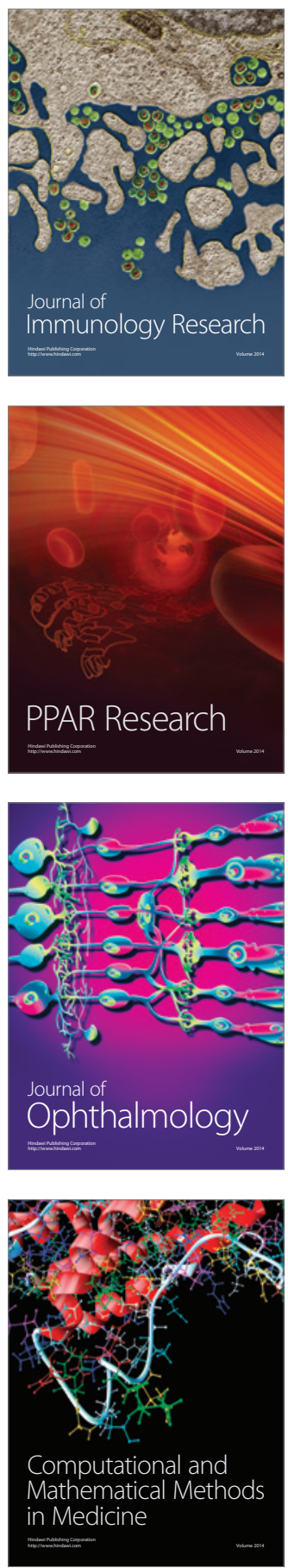

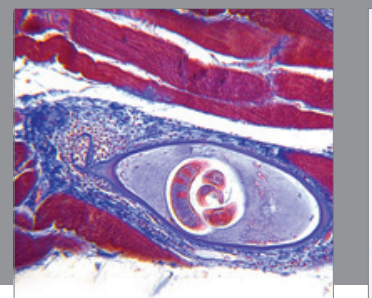

Gastroenterology

Research and Practice
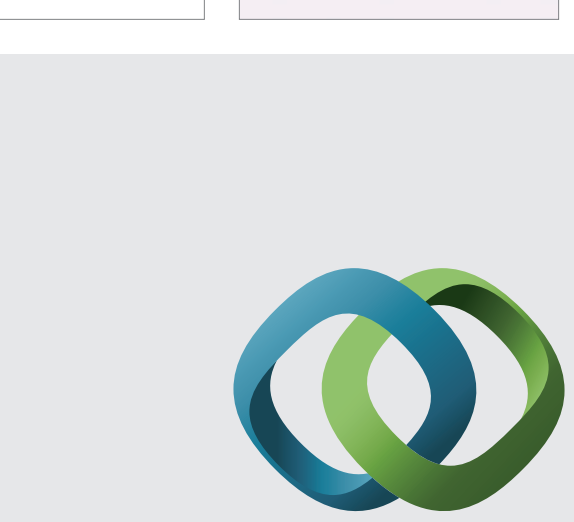

\section{Hindawi}

Submit your manuscripts at

http://www.hindawi.com
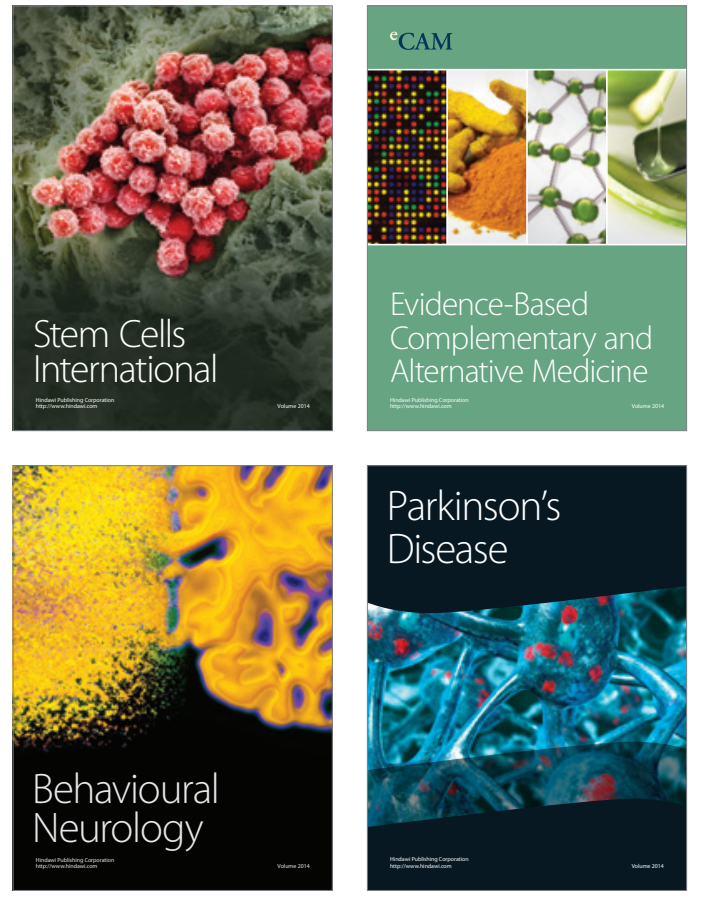
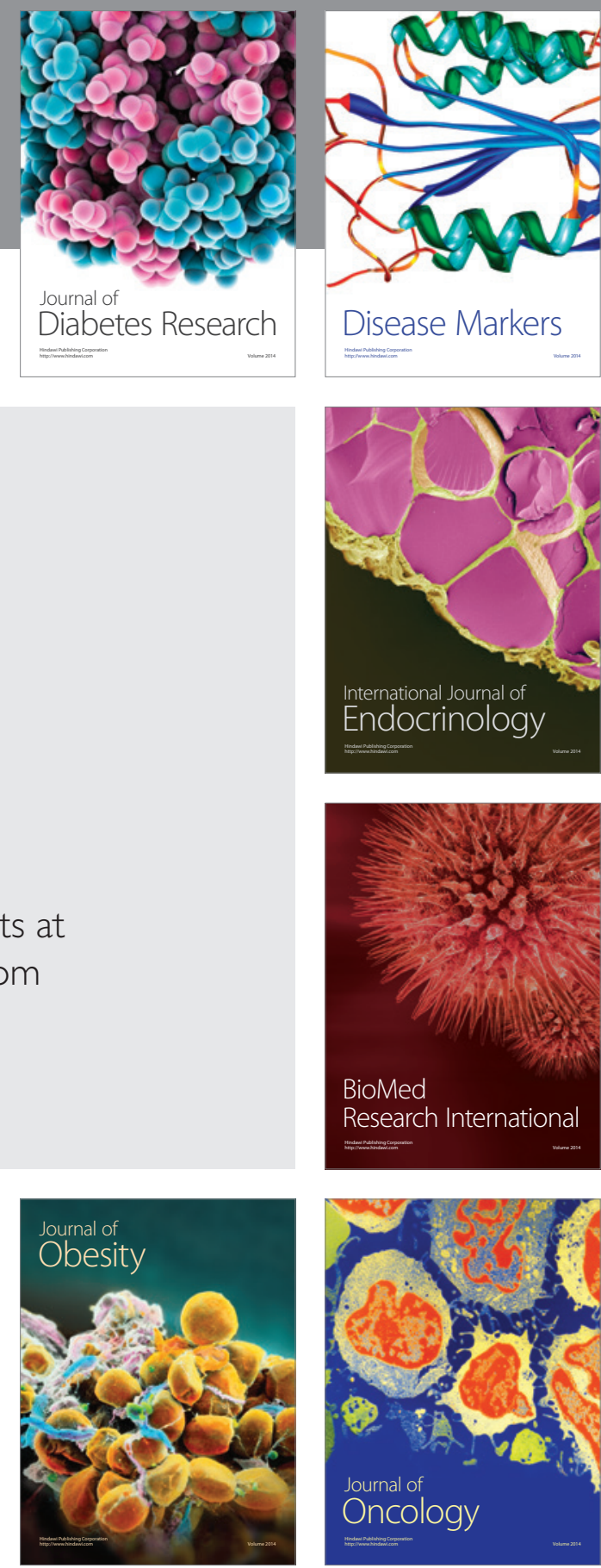

Disease Markers
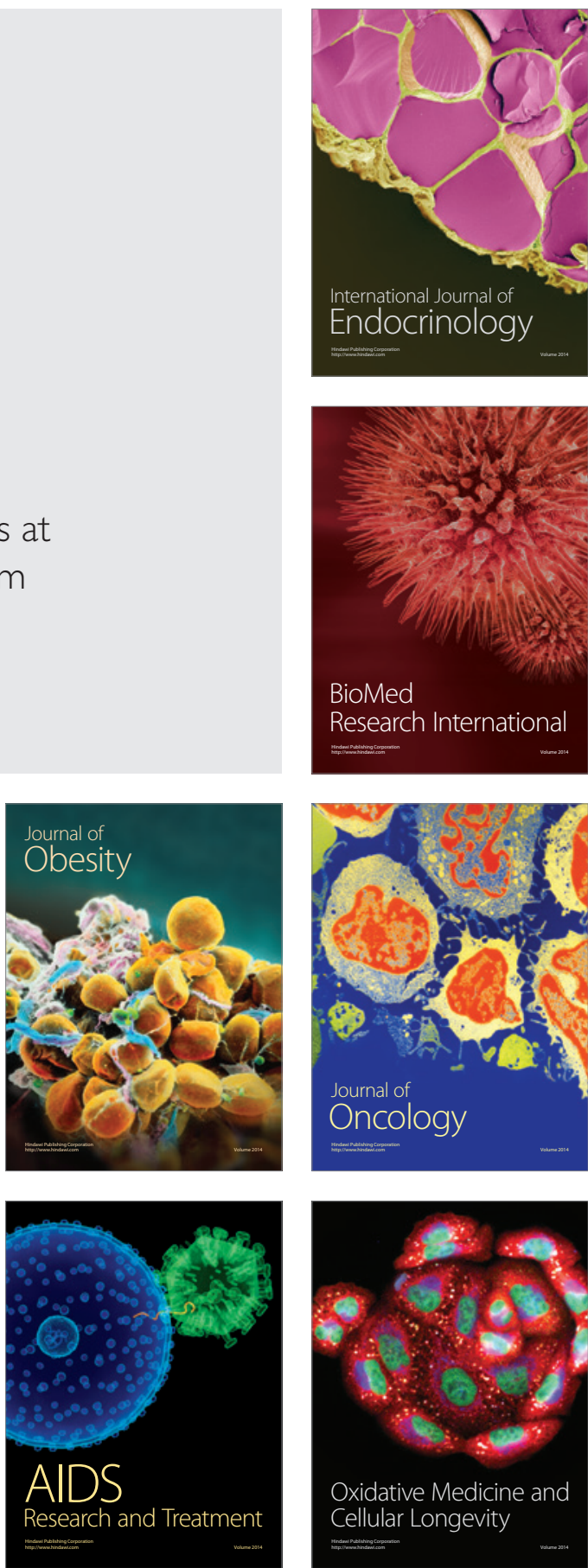